\title{
El Corredor Verde del Guadiamar como estudio de caso en el proyecto europeo RECARE
}

\author{
T. Marañón ${ }^{1, *}$, E. Madejón ${ }^{1}$ \\ (1) Instituto de Recursos Naturales y Agrobiología, CSIC, Avenida Reina Mercedes 10, 41012 Sevilla.
}

* Autor de correspondencia: T. Marañón [teodoro@irnase.csic.es]

> Recibido el 07 de marzo de 2014, aceptado el 25 de marzo de 2014.

Marañón, T., Madejón, E. 2014. El Corredor Verde del Guadiamar como estudio de caso en el proyecto europeo RECARE. Ecosistemas 23(1):81-82. Doi.: 10.7818/ECOS.2014.23-1.16

Durante los días 13 a 17 de enero de 2014 tuvo lugar en Valencia la reunión inicial (kick-off meeting) del proyecto europeo RECARE - Preventing and remediating degradation of soils in Europe through Land Care (http://www.recare-project.eu/). Entre sus objetivos se incluye el diseño, la selección y la implementación de medidas para la prevención, recuperación y restauración de zonas degradadas.

Se han contemplado 11 tipos principales de amenazas que causan la degradación de los suelos a escala europea: erosión por agua y por viento, salinización, compactación, sellado, desertificación, inundación, pérdida de materia orgánica en suelos minerales y en suelos orgánicos, contaminación y pérdida de biodiversidad del suelo. Los problemas de degradación resultan de la combinación de factores biofísicos, socio-económicos y políticos y son por definición específicos del sitio. Por tanto, se han designado 17 estudios de caso distribuidos por Europa para abordar la problemática de los suelos degradados. Uno de ellos es el Corredor Verde del Guadiamar (Sevilla) como ejemplo de zona degradada por contaminación por elementos traza, ocasionada por un vertido minero, y donde se han aplicado diferentes técnicas de recuperación y restauración de suelos.

Nos reunimos en Valencia unos 50 participantes (Fig. 1), representando a los 27 organismos de 18 países que forman el consorcio RECARE. La reunión fue abierta por Coen Ritsema (Universidad de Wageningen) como coordinador del proyecto. Cada responsable de los 11 módulos (work packages) del proyecto explicó su desarrollo durante los próximos 5 años (hasta 30 octubre 2018) y el calendario para los 26 entregables previstos. El núcleo central del proyecto (módulos 3 a 7) estará dedicado a los estudios de caso.

El equipo del Instituto de Recursos Naturales y Agrobiología (IRNAS, CSIC), junto con la empresa Evenor-Tech, será responsable de abordar la amenaza "contaminación del suelo" y desarrollar el estudio de caso del Corredor Verde del Guadiamar. Las princi- pales tareas serán: (1) evaluar el estado actual de degradación y conservación del área afectada, 16 años después del vertido minero de Aznalcóllar; (2) evaluar y analizar, junto con los gestores y grupos de interés, la eficacia de las medidas de prevención, recuperación y restauración aplicadas; (3) implementar ensayos sobre nuevas técnicas de recuperación y restauración para estos suelos (aún contaminados residualmente) y analizar sus costes y beneficios; y (4) estudiar la eficacia de las medidas para recuperar la funcionalidad del suelo y garantizar la provisión de servicios ecosistémicos.

El principal reto del proyecto consiste en escalar los resultados de los estudios de caso al nivel europeo (módulos 8 y 9). Entre los objetivos está extraer conclusiones generales sobre cada tipo de amenaza o agente de degradación, y sobre la forma más efectiva de prevenirlos o de paliar sus impactos. Mediante modelización, se propone realizar una evaluación integrada, a escala europea, de los principales impulsores externos que provocan los diferentes tipos de degradación del suelo, analizar el impacto y los compromisos entre las diferentes medidas de mitigación, remediación o restauración. Un resultado importante será la predicción de los posibles impactos sobre el secuestro de carbono, la disponibilidad de agua o la producción de alimentos. Al final del proyecto se propondrán recomendaciones para una política de protección del suelo a escala europea.

Durante la reunión disfrutamos de una visita de campo organizada por Artemi Cerdà (Universidad de Valencia). Pudimos observar diferentes ejemplos de gestión de sistemas agrarios (cultivos de cítricos, huertas y viñedos), algunos con problemas severos de erosión del suelo; así como sistemas forestales en la Sierra de Enguera (Fig.1) con problemas asociados al riesgo de incendios. Fue también una oportunidad para interaccionar con diversos gestores y representantes de grupos de interés que participaron en la visita. 


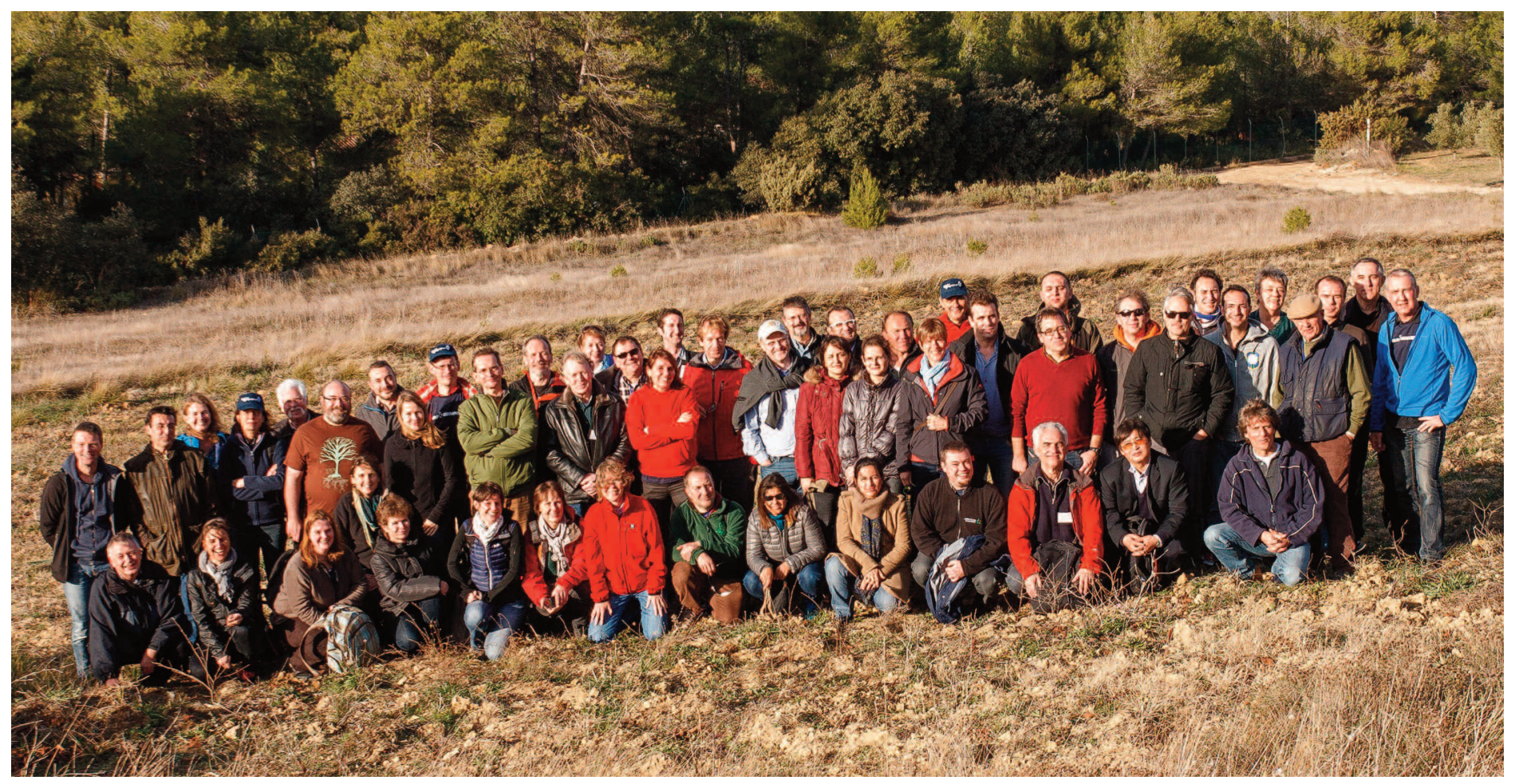

Figura 1. Participantes del proyecto RECARE en la visita a la Sierra de Enguera, Valencia (Foto: Erik van den Elsen). 